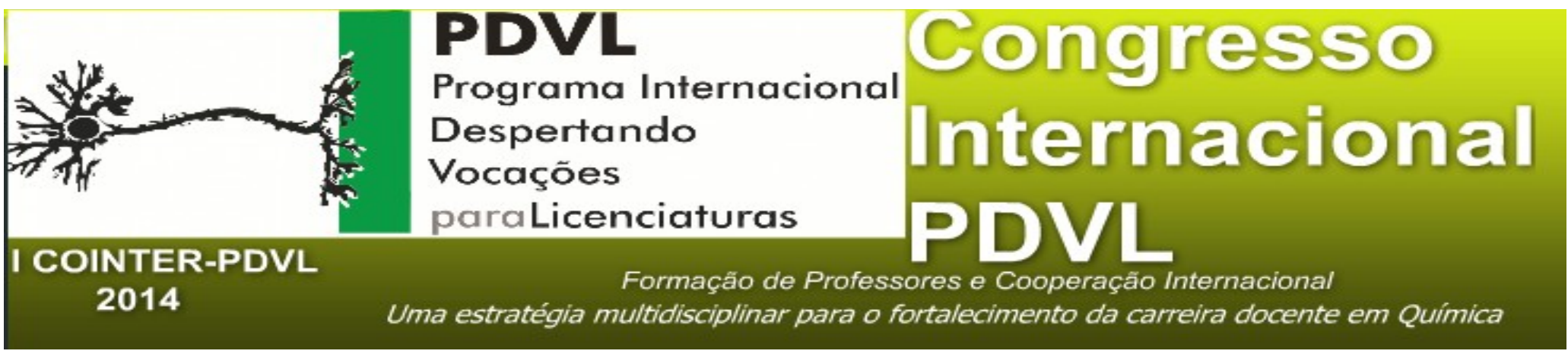

\title{
A Importância Do Ensino de Biossegurança Nas Escolas
}

\author{
Apresentação: Pôster
}

\begin{abstract}
Fernanda Alda da Silva ${ }^{11}$; Maria Rosana de Souza Ferreira ${ }^{22}$; Silvio Francisco da Silva ${ }^{33}$; Francisco Marques de Assis ${ }^{44}$
\end{abstract}

\section{Introdução}

Com o aumento do acesso tecnológico para as escolas e a inserção de equipamentos e laboratórios para o ensino é de suma importância o conhecimento sobre a segurança necessária nesse ambiente. Nesse contexto o ensino de biossegurança se torna extremamente necessário para o conhecimento da preservação do ambiente do laboratório e dos alunos que utilizam esse local.

O conhecimento científico-tecnológico é necessário para a atual sociedade em que nos encontramos. A aquisição de conhecimento científico através da experimentação e utilização do ambiente do laboratório contribui para uma formação prévia que será necessária para novas experiências como cursar um ensino superior. Em contrapartida, o ensino de biossegurança deve

1 Graduanda de Licenciatura em Ciências Biológicas na instituição UFPE, Bolsista de Iniciação Cientifica do CNPQ, e-mail: fernandaalda.s@hotmail.com

2 Graduanda de Licenciatura em Ciências Biológicas na instituição UFPE, e-mail: rosanamartins351@gmail.com;

3 Graduando de Licenciatura em Ciências Biológicas na instituição UFPE, e-mail: silviof46@hotmail.com

4 Docente na instituição IFPE, e-mail: francisco.marques@vitoria.ifpe.edu.br. 
estar intimamente atrelado a isso, pois além de um conhecimento técnico é composto também por componentes educacionais e sociais.

Este artigo tem como objetivo mostrar a necessidade e importância do ensino de biossegurança nas escolas, discutindo o assunto e refletindo sobre o mesmo.

\section{Fundamentação Teórica}

Biossegurança, etimologicamente, provém do radical grego bio, que significa vida e da palavra segurança, vida livre de perigo. Genericamente, pode ser considerada como ações que contribuem para a segurança das pessoas (Costa, 2005).

Um contingente significativo de especialistas em ensino das ciências propõe a substituição do verbalismo das aulas expositivas, e da grande maioria dos livros didáticos, por atividades experimentais (Fracalanza et al, 1986); embora outras estratégias de ensino possam adotar idêntico tratamento do conteúdo e alcançar resultados semelhantes, assim como proposto por Carraher (1986) no modelo cognitivo, no qual o ensino e a aprendizagem são vistos como "convites" à exploração e descoberta e o "aprender a pensar" assume maior importância que o simples "aprender informações".

O laboratório, além ser um local de aprendizagem, é um local de desenvolvimento do aluno como um todo. Segundo Capeletto (1992), existe uma fundamentação psicológica e pedagógica que sustenta a necessidade de proporcionar à criança e ao adolescente a oportunidade de, por um lado, exercitar habilidades como cooperação, concentração, organização, manipulação de equipamentos e, por outro, vivenciar o método científico, entendendo como tal a observação de fenômenos, o registro sistematizado de dados, a formulação e o teste de hipóteses e a inferência de conclusões.

Corroborando com essa idéia, Costa e Costa (2007) acreditam que a biossegurança deve ser ensinada em um contexto cidadão, incluindo não apenas o saber fazer, mas também o saber ser e o saber aprender. Para tanto, é primordial que o aluno ou o trabalhador não seja um mero reprodutor, mas sim um agente participativo-transformador no seu ambiente ocupacional. O processo educativo envolve uma ação de reflexão, e deve ultrapassar a idéia da simples normatização, e abranger, inclusive, aspectos relativos à ética, já que ela está implícita em praticamente todas as ações da biossegurança.

\section{Metodologia}


Para este estudo foram feitas pesquisas em artigos sobre o assunto. E surgiu a aplicabilidade de aulas sobre biossegurança que foram ministradas em turmas de ensino médio-técnico, três turmas de $2^{\circ}$ ano, no IFPE- Campus Vitória. Essas aulas foram com a utilização de data-show e apresentouse os equipamentos básicos para proteção utilizados em laboratórios (luvas, botas, jaleco, máscaras de pressurização, avental) e a construção de um mapa de risco para o laboratório de ensino de ciências que se encontra na mesma instituição.

\section{Resultados e Discussões}

Os alunos foram muito receptivos com as aulas, curiosos com os equipamentos e participativos durante todo o processo. Foi enfatizada a importância desse conhecimento científicotecnológico para os alunos e levado em conta as novas possibilidades a partir do mesmo.

Percebemos também que a biossegurança é um produto das ações de cada um, consequências e envolve práticas sociais e culturais. Por esse motivo o conhecimento correto desse assunto deve ser inserido e apresentado aos alunos assim que possível e não deixado apenas para o ensino superior, onde muitas vezes até nele mesmo não existe essa devida orientação, os alunos só aprendem na prática o que se deve ou não fazer no ambiente do laboratório.

\section{Conclusões}

Concluímos que tanto o ensino de biossegurança é de extrema importância como conhecimento para autopreservação das pessoas e do ambiente, como a importância do acesso a experimentações através do ambiente do laboratório.

Percebe-se também que é uma ferramenta para despertar desejos e vocações para futuras profissões, já que ao ter contato com novas experiências e possibilidades os estimula a conhecer mais das oportunidades e de suas próprias capacidades.

\section{Referências}


CAPELETTO, A. Biologia e Educação ambiental: Roteiros de trabalho. Editora Ática, 1992. p. 224.

CARRAHER, David. 1986. Educação Tradicional e Educação Moderna. In: CARRAHER, Terezinha Nunes (Org.). Aprender pensando: contribuições da psicologia cognitiva para a educação. Petrópolis: Vozes.

Costa, M.A.F. (2005). Construção do Conhecimento em Saúde: estudo sobre o ensino de biossegurança em cursos de nível médio da área de saúde da Fundação Oswaldo Cruz. Tese de Doutorado, Programa de Pós-Graduação em Ensino de Biociências e Saúde, Instituto Oswaldo Cruz. Rio de Janeiro, RJ.

Costa, M.A. e Costa, M.F.B. (2007). A Biossegurança na formação profissional em Saúde: ampliando o debate. Em: Pereira, I.B. e Ribeiro, C.G. (Ed.). Estudos de Politecnia e Saúde (pp. 253-272). Rio de Janeiro: Escola Politécnica de Saúde Joaquim Venâncio, Fiocruz.

FRACALANZA, H. et al. O Ensino de Ciências no $1^{\circ}$ grau. São Paulo: Atual. 1986. p.124. 